\title{
Influence of the Slope Shape on Seismic Stability of a Slope
}

\author{
Zhaopeng Zhang $\mathbb{D}^{1}{ }^{1}$ Chaoyu Chang, ${ }^{2}$ and Zhiyi Zhao' \\ ${ }^{1}$ North University of China, Taiyuan, China \\ ${ }^{2}$ Institute of Disaster Prevention, Sanhe, China \\ Correspondence should be addressed to Zhaopeng Zhang; jidazhangzhaopeng@126.com
}

Received 4 May 2020; Revised 7 July 2020; Accepted 29 July 2020; Published 14 August 2020

Academic Editor: Paolo Castaldo

Copyright (c) 2020 Zhaopeng Zhang et al. This is an open access article distributed under the Creative Commons Attribution License, which permits unrestricted use, distribution, and reproduction in any medium, provided the original work is properly cited.

\begin{abstract}
The slope shape is one of the most intuitive factors affecting the seismic stability of a slope. However, current research on this subject is mainly focused on statistical analysis and seismic response law, and the influence on seismic stability evaluation of the slope is rarely discussed. Furthermore, slope shapes are often simplified for easy numerical model building. In view of this, five slope models with different slope shapes are considered, and the time-history analysis method and Newmark method are chosen to evaluate the seismic stability of these slope models under different amplitudes. The purpose of this paper is to compare the seismic stability of slopes with different slope shapes and to study the feasibility of simplifying the slope shape when evaluating the seismic stability of a slope.
\end{abstract}

\section{Introduction}

In reality, many factors affect the seismic stability of a slope, such as geological structures, hydrogeological conditions, pore distribution, and structures adjacent to slopes. However, the most intuitive one is still the geometry of the slope. The parameters affecting the geometry of the slope mainly include the slope height, slope angle, and slope shape [1]. Nowadays, research on these geometrical parameters of slope under seismic mainly focuses on the slope height, slope angle, and even the coupling between them [2,3]; however, for the slope shape, due to the complexity of the model construction, most studies have simplified it to linear shape, so the research is still limited in this field.

Based on the shape of undulations in nature, the slope shape can be roughly divided into three types: linear, convex, and concave (shown in Figure 1). Wu et al. [4] used a mathematical statistics method and GIS technique to study the influence of slope shape on landslide development in the Three Gorges Reservoir region of China. Ren and Yao [5] studied the seismic response of soil slopes with different slope shapes under different amplitudes. On this basis, Yan et al. [6] studied the effects of slope shape on the displacement response of rock slopes under the influence of simple harmonics with different amplitudes and frequencies. He et al. [7] studied the failure progress of soil slopes with different slope shapes by a one-way vibration test bed. Qiu et al. [8] studied the influence of slope shape on the seismic response of gravel-soil slopes under conditions of oblique incident seismic waves. Düzgün and Budak [9] studied the differences in seismic responses between a single-faced slope and a ridge. Zhou et al. [2] studied the influence of different seismic coefficients on the stability of convex slope under 3D conditions.

In summary, it can be seen that the current research on seismic stability of the slope shape mainly focuses on statistical analysis and seismic response laws, and the stability evaluation of the slope has rarely been discussed. Furthermore, as stated above, to facilitate analysis and design, most of the numerical models ignore the influence of the slope shape; that is, the curved slopes (i.e., concave and convex slopes) are replaced by a linear slope, which may lead a great error between the calculation result and the actual result. In view of this, convex and concave slope models are established in this paper, and then, with them as the templates, two kinds of simplified slope models with polyline and linear shapes are established, respectively. Based on the stress field calculated by GeoStudio software, the time-history analysis 


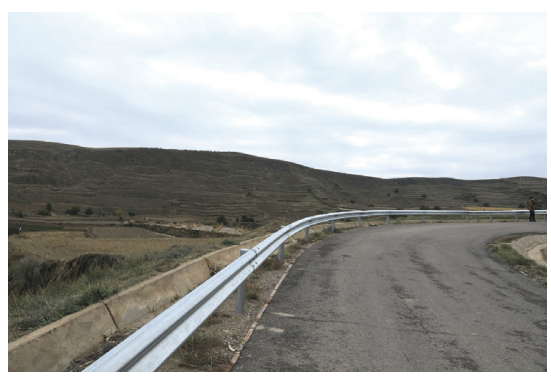

(a)

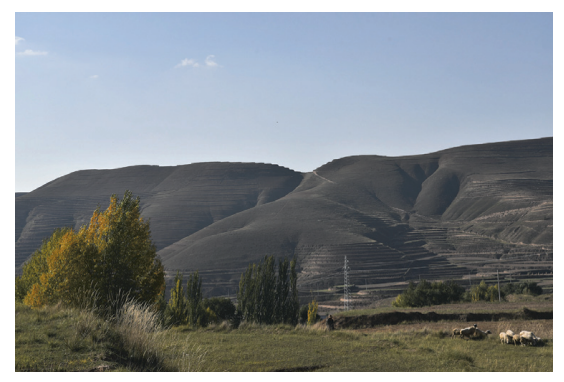

(b)

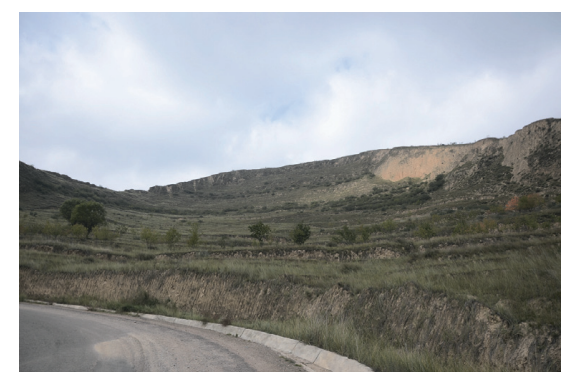

(c)

Figure 1: The slope shapes. (a) Linear. (b) Convex. (c) Concave.

method and Newmark method are used to analyze the seismic stability of slope models, and the safety factor and permanent displacement are chosen as the evaluation indexes to compare the seismic stability of slopes with different slope shapes and to study the feasibility of simplifying the slope shape when evaluating the seismic stability of slope. The detailed calculation process is shown in Figure 2.

\section{Numerical Models}

2.1. Model and Material Parameters. According to calculating flow chart, firstly, convex and concave slope models are constructed (shown in Figures 3(a) and 3(c)); Figures 3(b) and 3(d) show the slope models with the polyline shape after simplifying convex and concave slope models, respectively, and for the convenience of distinguishing, according to the relationship between the turning direction and slope direction, exterior and interior polyline shape slopes are defined, respectively; Figure 4 shows a slope model with a linear slope shape, which is also the most common slope shape in numerical analysis.

To fully reflect the influence of the slope shape on seismic stability of slopes, all numerical models are set as homogeneous soil slopes, and the analyses ignore the effect of groundwater. Except for the slope shape, the boundary range and the mesh size and soil parameters of all slope models are consistent, and the corresponding soil parameters are shown in Table 1.

2.2. Location of the Failure Surface. To avoid the influence of different failure surface positions on the calculation results, the same failure surface is selected for all slope models (shown in Figure 5; the abscissa value of the center of the failure surface is 55.09 , and the ordinate value is 55.10). The safety factors under static condition of each model corresponding to the sliding surface are shown in Table 2.

2.3. Seismic Waves. To study the influence of seismic on the stability of slopes with different slope shapes, the El Centro wave is selected as the incident wave for dynamic analysis and input horizontally from the bottom of the models; the acceleration time-history curves and corresponding Fourier spectrum are shown in Figure 6.

\section{Method}

At present, the main evaluation methods of slope seismic stability are the pseudostatic method, time-history analysis method, and Newmark method. Considering that the pseudostatic method ignores the time effect of seismic waves, in this paper, the time-history analysis method and Newmark method are used to evaluate the seismic stability of slopes with different slope shapes based on the coupling of QUAKE/W and SLOPE/W modules in GeoStudio software. The linear-elastic constitutive model is used to calculate the stress field (side boundary conditions are specified as zero $x$ and zero $y$-displacement, respectively, when calculating the static and dynamic stress fields of the model, and the bottom of the model is always constrained in two directions (GEOSLOPE International Ltd.)), and the Mohr-Coulomb constitutive model is used to calculate the slope stability.

3.1. Time-History Analysis Method. The total stress of slope under seismic is regarded as the superposition of static stress field and dynamic stress field when the time-history analysis method is used [10], so under the time-history analysis method, the safety factor (SF) which is defined as the ratio of antisliding force to sliding force on the sliding surface is as follows:

$$
\mathrm{SF}=\frac{\int_{\Gamma} \tau_{f}(t) \mathrm{d} \Gamma}{\int_{\Gamma} \tau(t) \mathrm{d} \Gamma},
$$

where $\tau_{f}(t)$ and $\tau(t)$ are the shear strength and shear stress of any microelement at $t$ time on the sliding surface and $\mathrm{d} \Gamma$ is the microelement area of the sliding surface. Under the condition of Coulomb strength theory, equation (1) can be transformed into

$$
\mathrm{SF}=\frac{\sum_{i}\left\{c_{i}+\left[\sigma_{s, i}+\sigma_{d, i}(t)\right] \tan \varphi_{i}\right\} \Gamma_{i}}{\sum_{i}\left[\tau_{s, i}+\tau_{d, i}(t)\right] \Gamma_{i}},
$$

where $c_{i}$ and $\varphi_{i}$ are the cohesion and internal friction angle of the $i$ th element, $\sigma_{s, i}$ and $\tau_{s, i}$ are the normal stress and shear stress under static condition, and $\sigma_{d, i}(t)$ and $\tau_{d, i}(t)$ are the additional normal stress and shear stress at time $t$ under seismic.

According to equation (2), the safety factor is a function that changes with time; however, in order to facilitate 


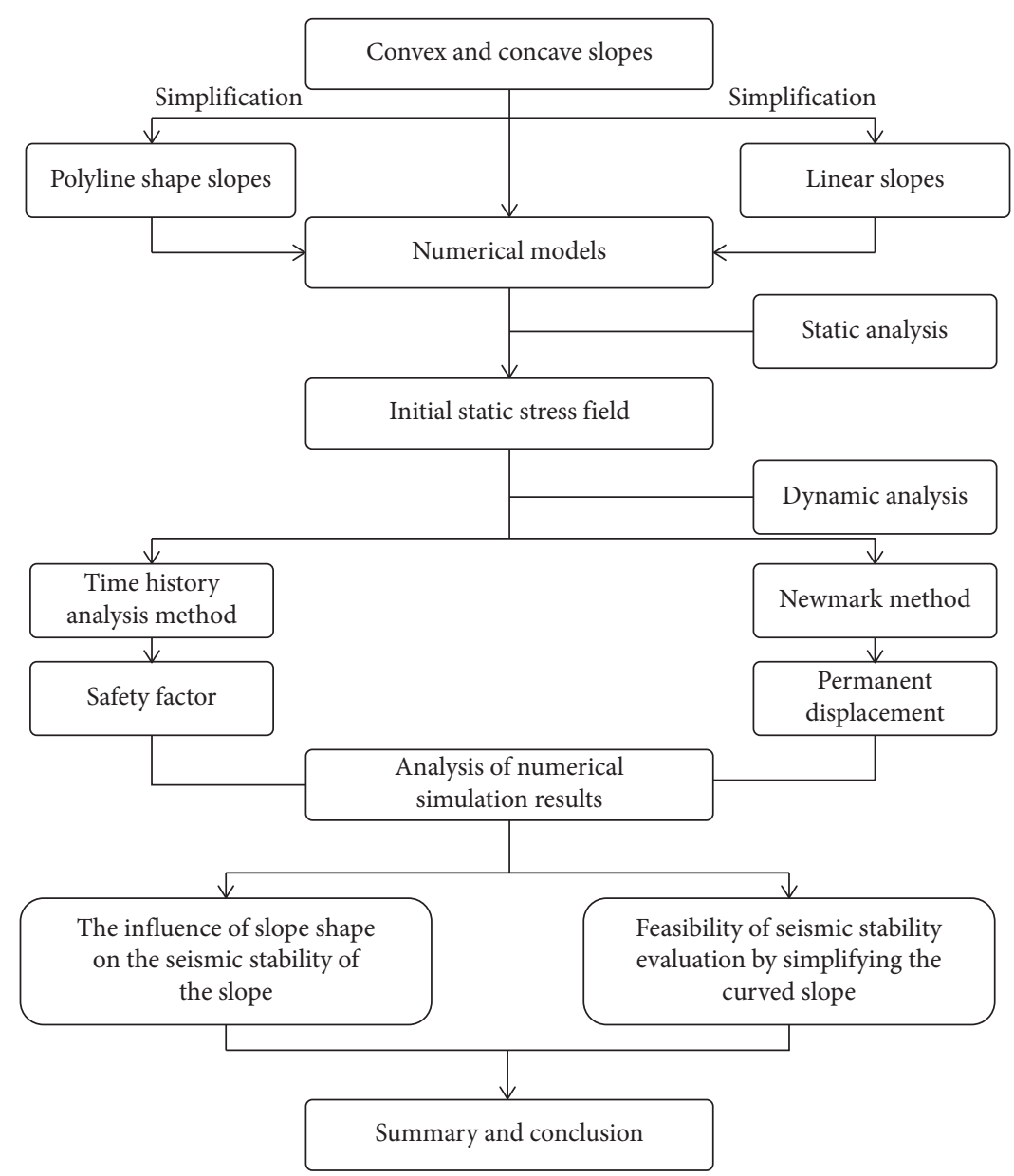

FIgUre 2: Calculating flow chart.

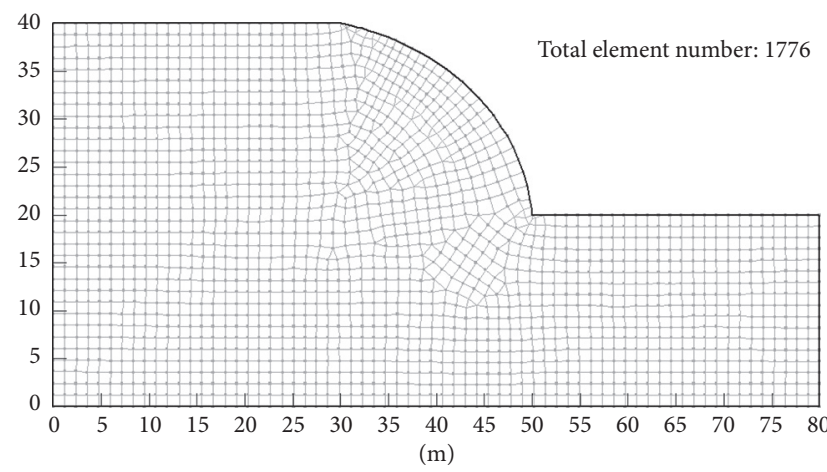

(a)

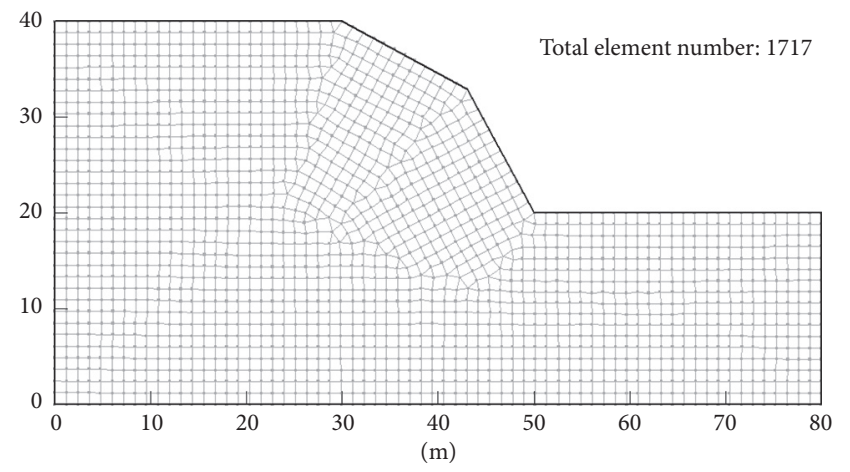

(b)

Figure 3: Continued. 


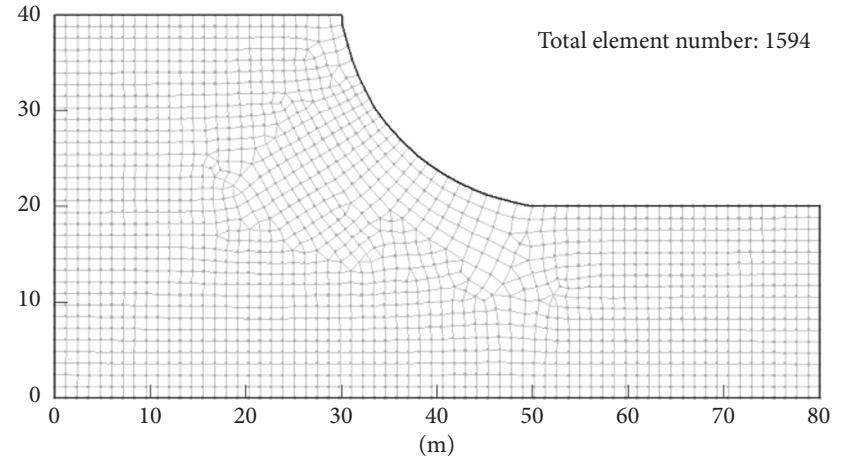

(c)

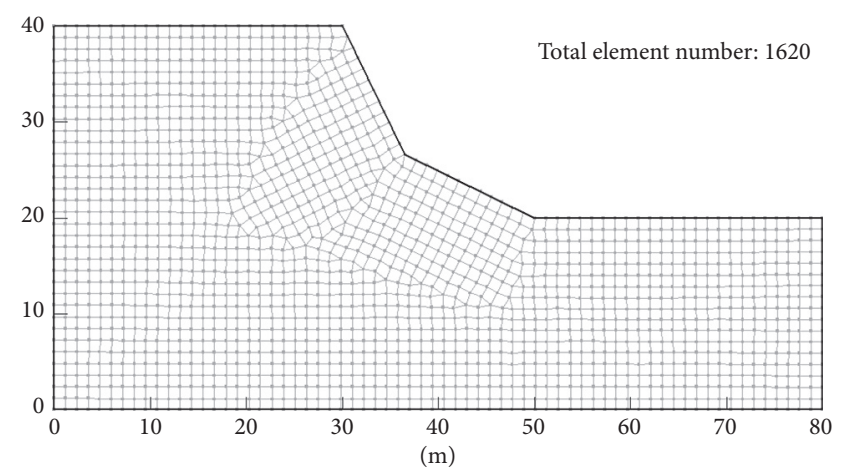

(d)

Figure 3: Models with different slope shapes. (a) Convex slope. (b) Exterior polyline shape slope. (c) Concave slope. (d) Interior polyline shape slope.

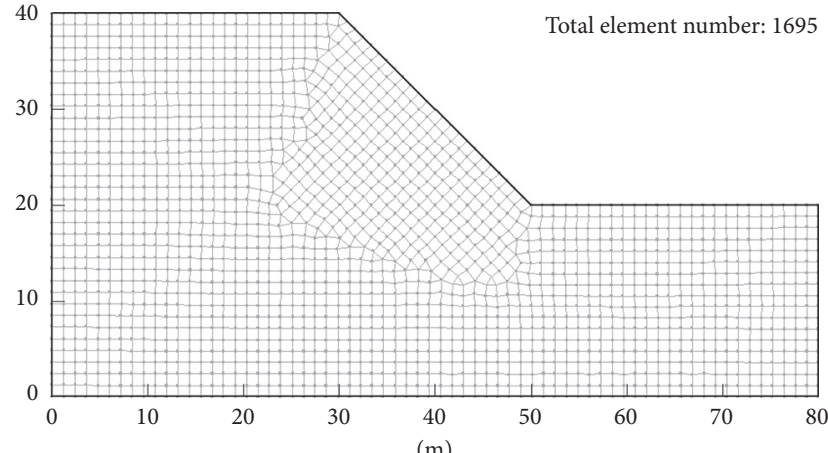

FIGURE 4: Slope model with a linear slope shape.

TABle 1: Material parameters.

\begin{tabular}{lcccc}
\hline$E(\mathrm{kPa})$ & $v$ & $c(\mathrm{kPa})$ & $\varphi(\mathrm{deg})$ & $\gamma\left(\mathrm{kN} / \mathrm{m}^{3}\right)$ \\
\hline 20000 & 0.33 & 22 & 23 & 19 \\
\hline
\end{tabular}

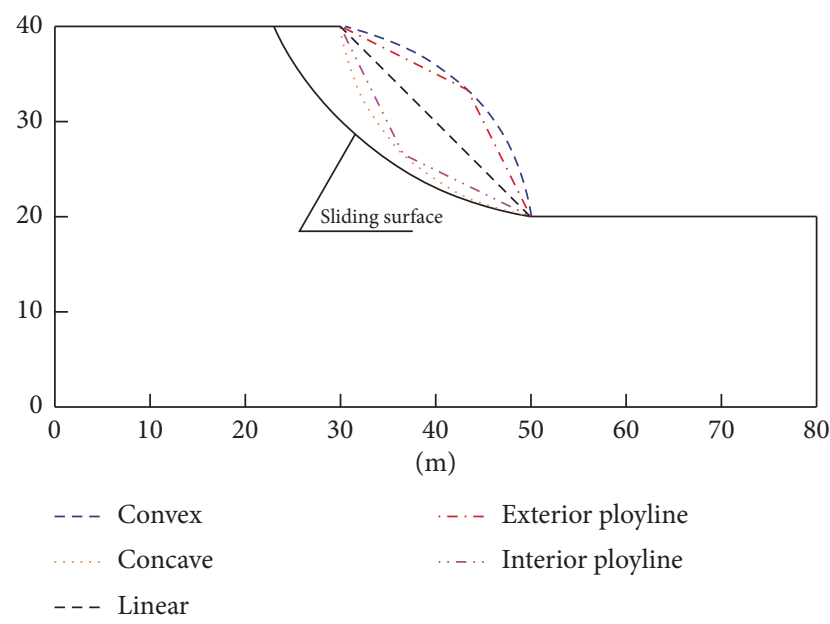

Figure 5: The location of the failure surface for the models.
TABLE 2: Safety factors under static condition.

\begin{tabular}{lccccc}
\hline $\begin{array}{l}\text { Slope } \\
\text { shape }\end{array}$ & Convex & $\begin{array}{l}\text { Exterior } \\
\text { polyline }\end{array}$ & Linear & $\begin{array}{c}\text { Interior } \\
\text { polyline }\end{array}$ & Concave \\
\hline $\begin{array}{l}\text { Safety } \\
\text { factor }\end{array}$ & 1.27 & 1.23 & 1.14 & 1.13 & 1.13 \\
\hline
\end{tabular}

engineering application, a fixed value is usually selected to represent the overall stability of slopes under the influence of seismic forces. Different standards, e.g., the minimum dynamic safety factor $[11,12]$, minimum mean safety factor [13], average safety factor [14], and safety factor of reliability [15], are considered. Among these evaluation standards, the minimum dynamic safety factor, which is the minimum value of the safety factor time-history curve, is the most commonly used, but it is too conservative as an evaluation standard because it only appears at a certain moment [13]. Therefore, in addition to the minimum dynamic safety factor, the permanent displacement calculated by the Newmark method is also chosen as the index with which the seismic stability of the slope is evaluated.

3.2. Newmark Method. The method proposed by Newmark [16], after years of development (e.g., [17-19]), has been widely used for the seismic stability evaluation of slopes. The basic principle of the method is that double integration of the area under the acceleration versus the time curve of the sliding mass where the acceleration exceeds the critical acceleration gives the permanent displacement of the sliding mass during the seismic, which is used as the evaluation criterion of slope stability. The formula for permanent displacement $U$ is expressed as follows:

$$
U=\iint\left[a(t)-a_{c}\right] \mathrm{d} t \mathrm{~d} t,
$$

where $a_{c}$ is the critical acceleration of the sliding mass (i.e., the acceleration of sliding mass corresponding to a safety factor of 1.0) and $a(t)$ is the portion of the acceleration versus time curve that exceeds $a_{c}$. 


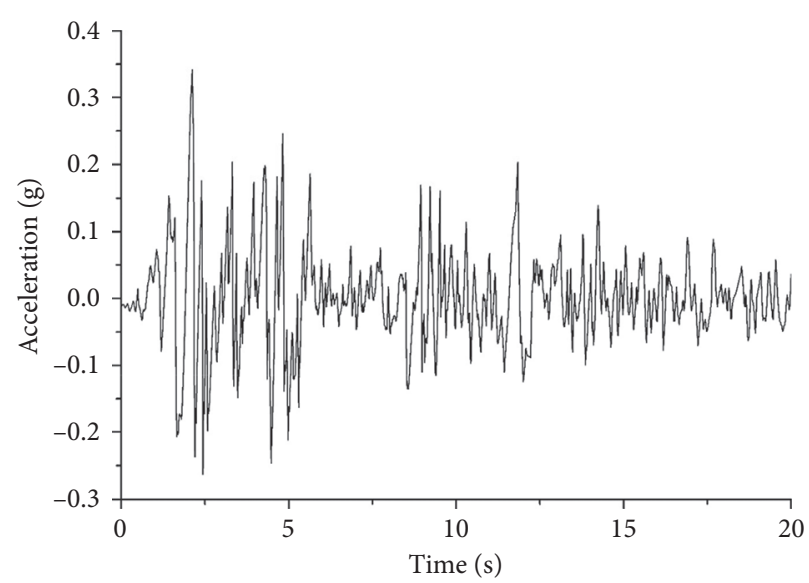

(a)

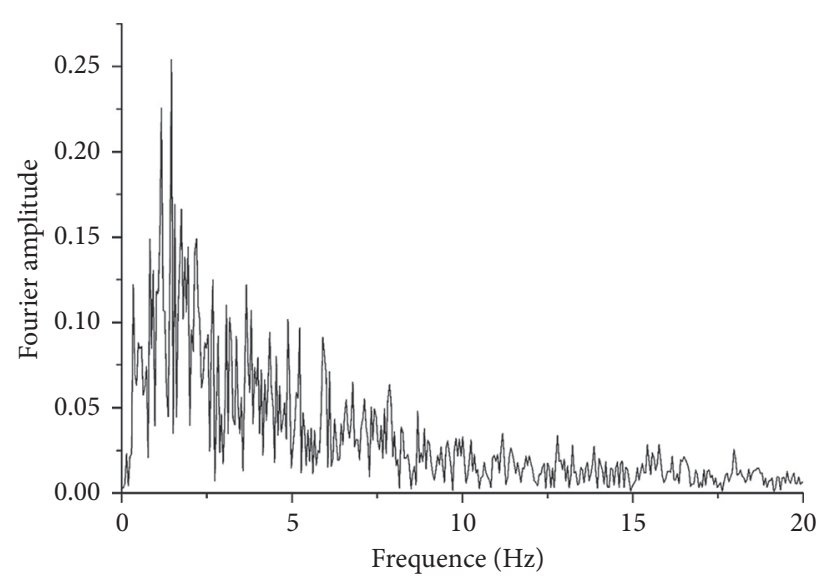

(b)

Figure 6: Seismic waves. (a) Acceleration time-history curves. (b) Fourier spectrum.

\section{Results and Discussion}

The amplitude of the El Centro wave is adjusted to 0.05, 0.10, 0.15 , and $0.20 \mathrm{~g}$, respectively, and input horizontally from the bottom of slope models after baseline correction.

4.1. Minimum Dynamic Safety Factor. Figure 7 shows the curves of the minimum dynamic safety factor and amplitude; it is found that, with the increase of amplitude, the minimum dynamic safety factor of each slope model decreases linearly, and the decreasing rate of the convex slope and concave slope is higher than that of the corresponding polyline shape slopes. However, the safety factor of the concave slope is greater than that of the interior polyline shape slope under the static condition, so when the amplitude is small, the sequence of seismic stability of slopes with different shapes from high to low is concave slope, interior polyline shape slope, linear slope, exterior polyline shape slope, and convex slope, and when the amplitude is large, the sequence of seismic stability of slopes with different shapes from high to low is interior polyline shape slope, concave slope, linear slope, exterior polyline shape slope, and convex slope.

From Tables 3 and 4, it is found that, with the increase of the amplitude, the difference of the minimum dynamic safety factor will gradually increase when the convex slope is simplified to an exterior polyline shape slope or a linear slope; however, when the concave slope is simplified to an interior polyline shape slope, the difference will decrease first and then increase, but it is always less than $1.8 \%$; when the concave slope is simplified to a linear slope, the difference will decrease gradually, but it is also greater than $8.0 \%$. In addition, compared with the difference of the simplifying convex or concave slope to the polyline shape slope, the difference of the simplifying convex or concave slope to the linear slope will be greater, especially when the amplitude is large.

4.2. Permanent Displacement. Figure 8 shows the curves of permanent displacement and amplitude; it is found that, with the increase of amplitude, the permanent displacement

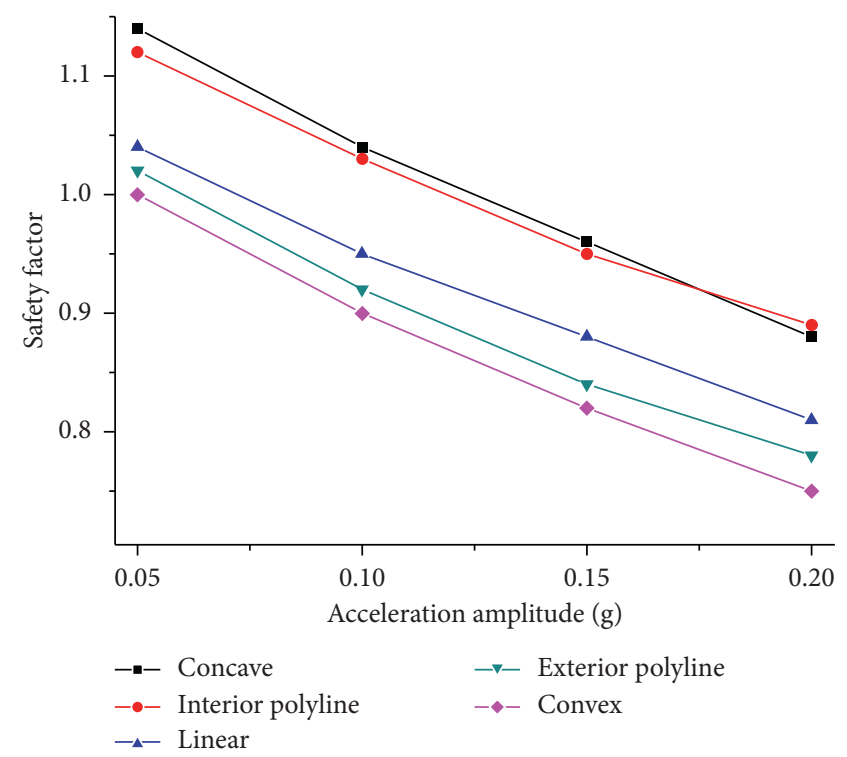

FIgURE 7: Curves of the minimum dynamic safety factor and amplitude.

of each slope model increases gradually, and under the same amplitude, the sequence of seismic stability of slopes with different shapes from high to low is approximately interior polyline shape slope, concave slope, linear slope, exterior polyline shape slope, and convex slope.

From Tables 5 and 6, it is found that, with the increase of amplitude, no matter whether the convex slope or concave slope is simplified, the difference of permanent displacement is basically increasing, and compared with the simplified the convex slope or concave slope to the polyline shape slope, the difference of permanent displacement is larger when it is simplified to linear slope.

Compared with the calculation results of the time-history analysis method, it can be seen that the conclusions are not completely consistent. This is because the permanent displacement is a cumulative deformation. If the acceleration of sliding mass generated by seismic is always less than 
TABle 3: Minimum dynamic safety factor of the convex slope, exterior polyline shape slope, and linear slope.

\begin{tabular}{lccccc}
\hline Amplitudes $(g)$ & Convex slope & $\begin{array}{c}\text { Exterior polyline } \\
\text { shape slope }\end{array}$ & $\begin{array}{c}\text { Linear } \\
\text { slope }\end{array}$ & $\begin{array}{c}\text { Difference with exterior polyline } \\
\text { shape slope (convex slope, \%) }\end{array}$ & $\begin{array}{c}\text { Difference with linear slope } \\
\text { (convex slope, \%) }\end{array}$ \\
\hline 0.05 & 1.00 & 1.02 & 1.04 & 2.0 & 4.0 \\
0.1 & 0.90 & 0.92 & 0.95 & 2.2 & 5.6 \\
0.15 & 0.82 & 0.84 & 0.88 & 2.4 & 7.3 \\
0.2 & 0.75 & 0.78 & 0.81 & 4.0 & 8.0 \\
\hline
\end{tabular}

TABle 4: Minimum dynamic safety factor of the concave slope, interior polyline shape slope, and linear slope.

\begin{tabular}{lccccc}
\hline Amplitudes $(g)$ & Concave slope & $\begin{array}{c}\text { Interior polyline } \\
\text { shape slope }\end{array}$ & $\begin{array}{c}\text { Linear } \\
\text { slope }\end{array}$ & $\begin{array}{c}\text { Difference with interior polyline } \\
\text { shape slope (concave slope, \%) }\end{array}$ & $\begin{array}{c}\text { Difference with linear slope } \\
\text { (concave slope, \%) }\end{array}$ \\
\hline 0.05 & 1.14 & 1.12 & 1.04 & 1.8 & 8.8 \\
0.1 & 1.04 & 1.03 & 0.95 & 1 & 8.7 \\
0.15 & 0.96 & 0.95 & 0.88 & 1 & 8.3 \\
0.2 & 0.88 & 0.89 & 0.81 & 1.1 & 8.0 \\
\hline
\end{tabular}

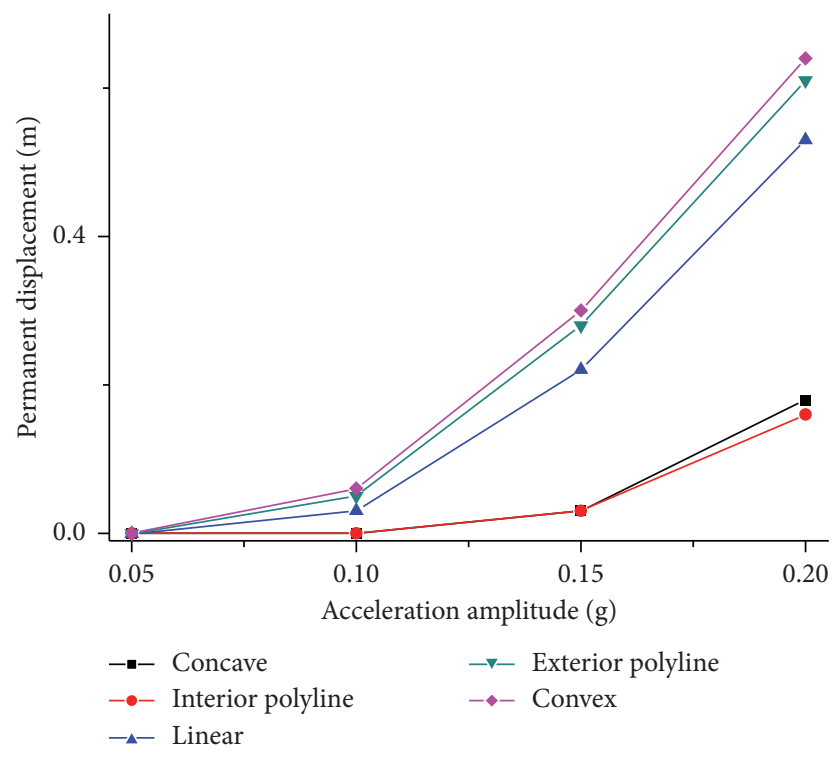

Figure 8: Curves of permanent displacement and amplitude.

TABle 5: Permanent displacement of the convex slope, exterior polyline shape slope, and linear slope.

\begin{tabular}{lccccc}
\hline Amplitudes $(g)$ & Convex slope $(m)$ & $\begin{array}{c}\text { Exterior polyline } \\
\text { shape slope }(m)\end{array}$ & $\begin{array}{c}\text { Linear } \\
\text { slope }(m)\end{array}$ & $\begin{array}{c}\text { Difference with exterior polyline } \\
\text { shape slope (convex slope, } m \text { ) }\end{array}$ & $\begin{array}{c}\text { Difference with linear slope } \\
(\text { convex slope, } m \text { ) }\end{array}$ \\
\hline 0.05 & 0 & 0 & 0 & 0 & 0 \\
0.1 & 0.06 & 0.05 & 0.03 & 0.01 & 0.03 \\
0.15 & 0.30 & 0.28 & 0.22 & 0.02 & 0.08 \\
0.2 & 0.64 & 0.61 & 0.53 & 0.03 & 0.11 \\
\hline
\end{tabular}

TABle 6: Permanent displacement of the concave slope, interior polyline shape slope, and linear slope.

\begin{tabular}{lccccc}
\hline Amplitudes $(g)$ & Concave slope $(m)$ & $\begin{array}{c}\text { Interior polyline } \\
\text { shape slope }(m)\end{array}$ & $\begin{array}{c}\text { Linear } \\
\text { slope }(m)\end{array}$ & $\begin{array}{c}\text { Difference with interior polyline } \\
\text { shape slope (concave slope, } m \text { ) }\end{array}$ & $\begin{array}{c}\text { Difference with linear slope } \\
\text { (concave slope, } m \text { ) }\end{array}$ \\
\hline 0.05 & 0 & 0 & 0 & 0 & 0 \\
0.1 & 0 & 0 & 0.03 & 0 & 0.03 \\
0.15 & 0.03 & 0.03 & 0.22 & 0 & 0.19 \\
0.2 & 0.18 & 0.16 & 0.53 & 0.02 & 0.35 \\
\hline
\end{tabular}


its critical acceleration, the permanent displacement is zero. Therefore, this is one of the reasons why the time-history analysis method is also used in this paper, that is, to compare the seismic stability of slopes with zero permanent displacement.

\section{Conclusions}

In this paper, based on the time-history analysis method and Newmark method, the minimum dynamic safety factor and permanent displacement are used as evaluation indexes to study the influence of the slope shape on seismic stability of the slope; some conclusions can be found as follows:

(a) Since the calculation results of seismic stability of the concave slope and interior polyline shape slope are very close, the sequence of seismic stability of slopes with different shapes from high to low under the same amplitude is approximately interior polyline shape slope, concave slope, linear slope, exterior polyline shape slope, and convex slope

(b) Compared with the simplified slopes, the stability of the convex slope and concave slope are more significantly affected by seismic

(c) When calculating the seismic stability of slopes, the convex slope or concave slope can be simplified to a polyline shape slope, but it is not recommended to simplify it to a linear slope, especially in a high seismic intensity region

Note that, in order to study the feasibility of simplifying the slope shape when evaluating the seismic stability of slope, the same failure surface is selected for all slope models in this paper. The effect of different failure surfaces (e.g., the critical slip surface) on the calculation results will be explored in future research work.
Abbreviations
E: Young's modulus
$\gamma$ : Unit weight
$c$ : Cohesion
$v$ : Poisson ratio
$\varphi$ : Friction angle.

\section{Data Availability}

The (DATA TYPE) data used to support the findings of this study are included within the article.

\section{Conflicts of Interest}

The authors declare no conflicts of interest.

\section{Acknowledgments}

The authors acknowledge the support of Scientific and Technologial Innovation Programs of Higher Education Institutions in Shanxi (2019L0604) and Applied Basic Research Program of Shanxi Province (201801D221233).

\section{References}

[1] S. W. Qi, F. Q. Wu, C. L. Li et al., "Engineering geology analysis on stability of slope under earthquake," Chinese Journal of Rock Mechanics and Engineering, vol. 16, pp. 2792-2797, 2004.

[2] H. Zhou, G. Zheng, X. Yang, T. Li, and P. Yang, "Ultimate seismic bearing capacities and failure mechanisms for strip footings placed adjacent to slopes," Canadian Geotechnical Journal, vol. 56, no. 11, pp. 1729-1735, 2018.

[3] S. C. Yang, B. Leshchinsky, K. Cui et al., "Influence of failure mechanism on seismic bearing capacity factors for shallow foundations near slopes," Géotechnique, 2020.

[4] C. Y. Wu, J. P. Qiao, and L. B. Lan, "Research on slope shape of landslide based on GIS technique," Journal of Natural Disasters, vol. 14, no. 3, pp. 34-37, 2005.

[5] Z. M. Ren and L. K. Yao, "Stability of soil slope on the influence of the slope shape under seismic," Subgrade Engineering, vol. 5, pp. 5-7, 2008.

[6] Z. X. Yan, S. Shi, B. Dang et al., "Influence of the slope shape on the stability of rock slope under the seismic," Journal of Shangdong University of Science and Technology, vol. 32, no. 2, pp. 43-48, 2013.

[7] L. He, G. Wu, and Z. M. Zhao, "Model test of influence of slope surface morphology on dynamic deformation failure," Rock \& Soil Mechanics, vol. 35, no. 1, pp. 111-117, 2014.

[8] M. Qiu, H. Chen, and M. J. Tian, "Effect of slope shape on gravel-soil slope stability in obliquely incident seismic wave," Technology for Earthquake Disaster Prevention, vol. 10, no. 2, pp. 324-334, 2015.

[9] O. A. Düzgün and A. Budak, "Effects of surface shapes and geotechnical conditions on the ground motion," Ksce Journal of Civil Engineering, vol. 19, no. 5, pp. 1336-1346, 2015.

[10] L. T. Shao and H. J. Li, Soil Structure Stability Analysis, Finite Element Limit Equilibrium Method and Application, Science Press, Beijing, China, 2011.

[11] J. H. Zhang, J. W. Fan, and J. D. He, "Dynamic safety evaluation of slopes or dam foundations using rigid body spring element method," Chinese Journal of Rock Mechanics \& Engineering, vol. 18, no. 4, pp. 387-391, 1999.

[12] J. S. Bo, G. D. Xu, and L. P. Jing, "Seismic response and dynamic stability analysis of soil slopes," Earthquake Engineering and Engineering Vibration, vol. 21, no. 2, pp. 116-120, 2001.

[13] H. L. Liu, K. Fei, and Y. F. Gao, "Time history analysis method of slope seismic stability," Rock and Soil Mechanics, vol. 24, no. 4, pp. 553-560, 2003

[14] Z. Y. Wu, J. Y. Bo, H. S. Liu et al., "A method for evaluating dynamic safety factor rock slope seismic stability analysis," Journal of Disaster Prevention and Mitigation Engineering, vol. 24, no. 3, pp. 237-241, 2004.

[15] H. S. Liu, J. S. Bo, and J. B. Yang, "Simplified method for determining seismic safety factor of rock slope," Chinese Journal of Rock Mechanics and Engineering, vol. 31, no. 6, pp. 1107-1114, 2012.

[16] N. M. Newmark, "Effects of earthquakes on dams and embankments," Géotechnique, vol. 15, no. 2, pp. 139-160, 1965.

[17] A. G. Franklin and F. K. Chang, Permanent Displacements of Earth Embankments by Newmark Sliding Block Analysis, Army Engineer Waterways Experiment Station, Vicksburg, MO, USA, 1977. 
[18] J. D. Bray and T. Travasarou, "Simplified procedure for estimating earthquake-induced deviatoric slope displacements," Journal of Geotechnical and Geoenvironmental Engineering, vol. 133, no. 4, pp. 381-392, 2007.

[19] F. I. Makdisi and H. B. Seed, "A simplified procedure for estimating earthquake-induced deformations in dams and embankments," Journal of Geotechnical and Geoenvironmental Engineering, vol. 105, no. 12, pp. 1427-1434, 1978. 